\title{
Manufaktur dan Analisa Kekuatan Tarik Komposit Hybrid Serat Glass/Carbon untuk Aplikasi Pembuatan Blade Turbin Savonius
}

\author{
Muhammad Abdus Shomad, Ferriawan Yudhanto*, Rinasa Agistya Anugrah \\ Program Studi Teknologi Mesin, Program Vokasi, Universitas Muhammadiyah Yogyakarta, \\ Jl. Brawijaya, Tamantirto, Kasihan, Bantul, Yogyakarta 5518 \\ *Penulis korespondensi: ferriawan@umy.ac.id
}

Histori artikel: diserahkan 25 Oktober 2020, direviu 27 Oktober 2020, direvisi 30 Oktober 2020

\begin{abstract}
Blade design and material selection for savonius turbines need to accurate to produce high power input. This research aims to make the most robust blade material by vacuum infusion manufactured. The hybrid laminate composite applied in the manufacture of Savonius turbine blades consists of woven carbon fiber with chopped strand mat glass fiber and woven glass fiber. The variations of fiber composition comprised of five layers, namely 5An (5 layers of woven glass fiber), $5 A c$ (5 layers of chopped strand mat glass fiber), 2C-3An (2 woven carbon fiber-3 woven glass), and $2 C-3 A c$ ( 2 woven carbon fiber-3 chopped strand mat glass fiber). The results showed $2 C-3 A n$ for the best variation of hybrid laminate composite with the tensile strength of $219 \mathrm{MPa}$, with the modulus of elasticity of $6.8 \mathrm{GPa}$ and the smallest density was $1.21 \mathrm{~g} / \mathrm{cm}^{3}$.
\end{abstract}

Keywords: hybrid laminate composite, vacuum infusion, glass fiber, carbon fiber

DOI: https://doi.org/10.18196/jqt.020122

Web: https://journal.umy.ac.id/index.php/qt/article/view/10132

\section{PENDAHULUAN}

Turbin angin pada saat ini terus dikembangkan untuk penghasil energi listrik alternative dari gerak menjadi listrik. Pantai di pulau jawa memiliki kecepatan angin berkisar 2,5 hingga 4 $\mathrm{m} / \mathrm{s}$ menurut data pemetaan oleh Lembaga Penerbangan dan Antariksa Nasional (LAPAN, 2005). Penelitian blade turbin Savonius pernah dilakukan oleh Pradana et al., (2013) dengan menggunakan 2 blade dari bahan pipa PVC dan memiliki dimensi diameter $100 \mathrm{~mm}$ dan tinggi $360 \mathrm{~mm}$ dengan berat $0,8 \mathrm{Kg}$. Penelitian ini menguji kelengkungan dan massa blade. Semakin besar kelengkungan dan diameter blade maka hasil putaran semakin rendah dan menghasilkan daya yang kurang optimal. Kelengkungan yang rendah pada menghasilkan putaran yang lebih cepat sehingga menghasilkan daya lebih besar.

Penggunaan bahan serat gelas tipe E (E-Glass) acak panjang (chopped strand mat) diberi kode CSM dan anyam berlapis (woven roving) diberi kode WR dan dihibridisasi dengan serat sabut kelapa dengan kode SSK dengan susunan serat 6 lapis telah diteliti oleh Mawardi dan Hanif,
(2018). Susunan komposit hybrid laminate disusun dengan susunan 3 variasi lapisan yaitu; variasai $1 \quad[\mathrm{CSM} / \mathrm{SSK} / \mathrm{WR}]_{2}$, variasi 2 $\left[\mathrm{WR}_{2} / \mathrm{SSK}_{2} / \mathrm{WR}_{2}\right]$, dan variasi 3. [CSM/SSK/WR $2 / \mathrm{SSK} / \mathrm{CSM}]$. Hasil pengujian Tarik (ASTM D3039) dan didapat nilai terbaik pada kekuatan tarik pada variasi 2 sebesar 309 MPa dan modulus elastisitas sebesar 5,42 $\mathrm{GPa}$. Penggunaan serat anyam mempengaruhi nilai kekuatan tarik dan modulus elastisitas komposit hybrid lamina.

Yudhanto et al., (2016) meneliti penggunaan hybrid serat anyam E-Glass dengan anyaman serat alam Sisal. Matriks polimer yang digunakan adalah UPR (unsaturated polyester resin) BQTN-157 Ex. Susunan lapisan yang dibuat sebanyak 3 lapis dengan variasi FG-FGFG (3 serat gelas anyam), FG-S-FG (2 serat gelas anyam dan 1 serat anyam sisal), S-FG-S (2 serat sisal dan 1 serat gelas) dan terakhir S-SS (3 serat sisal). Hasil pengujian tarik didapat bahwa penambahan serat alam meningkatkan regangan dan menurunkan modulus elastisitas komposit. Hasil terbaik diperoleh pada susunan FG-FG-FG sebesar $133 \mathrm{MPa}$ dan terendah pada S-S-S sebesar $48 \mathrm{MPa}$. 
(a)

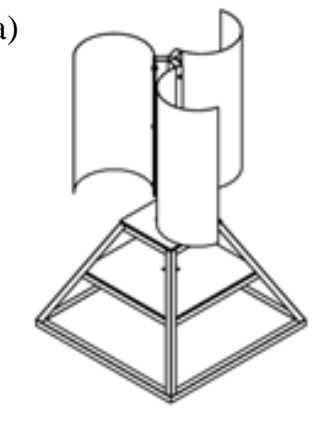

(b)

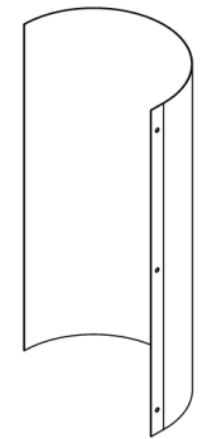

(c)

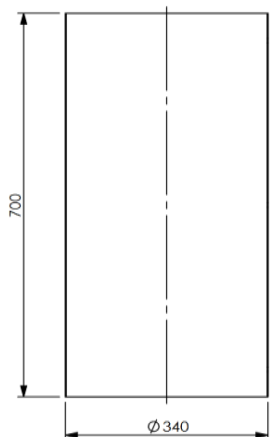

(d)

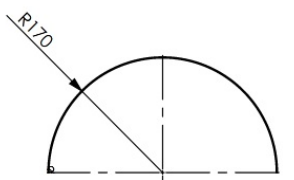

GAMBAR 2. (a) Disain blade turbin savonius, (b) bentuk blade, (c) ukuran blade, (d) radius blade (mm)

Modulus tertinggi diperoleh serat sintetis Gelas sebesar $40 \mathrm{GPa}$ dan paling kecil $5 \mathrm{GPa}$ untuk komposit serat alam Sisal. Hybrid komposit kekuatan tarik berkisar 68-117 $\mathrm{MPa}$ dan modulus elastisitas berkisar 6-11 GPa. Hal ini sesuai dengan penelitian Joseph et al., (1999).

Jesthi et al., (2018) melakukan penelitian pada komposit hybrid serat glass $(\mathrm{G})$ dan carbon (C) anyam. Jumlah lapisan komposit lamina yaitu 10 lapis dengan urutan susunan lapisan (stacking sequence) $[\mathrm{GCGGC}]_{\mathrm{s}}$ dan [CGGCG $]_{s}$. hasil yang diperoleh pada uji kekuatan Tarik memiliki nilai yang tidak berbeda jauh yaitu $305 \mathrm{MPa}$ dan modulus elastisitas 7,5 Gpa untuk [GCGGC] sedangkan untuk [CGGCG] $]_{\mathrm{s}}$ kekuatan Tarik sebesar 290 MPa akan tetapi modulus elastisitas lebih tinggi yaitu $9 \mathrm{GPa}$. Disimpulkan bahwa perubahan stacking sequence dapat mempengaruhi nilai modulus elastisitas secara signifikan.

Blade turbin savonius perlu di desain dengan tepat agar dapat menghasilkan daya yang besar pada saat diaplikasikan. Selain itu, pemilihan material dan bagaimana proses manufaktur blade juga akan mempengaruhi peforma blade. Berdasarkan permasalahan tersebut penulis meneliti komposisi dan sususan komposit hybride laminate yang akan digunakan dalam pembuatan blade agar nantinya menghasilkan material yang kuat serta kinerja turbin angin savonius dapat maksimal.

\section{METODE PENELITIAN}

Serat yang digunakan adalah chopped strand mat (CSM $220 \mathrm{gr} / \mathrm{m}^{2}$ E-Glass) dan woven roving (WR-200 gr $/ \mathrm{m}^{2}$ E-Glass) dan Fiber Carbon WR-200 gr/ $\mathrm{m}^{2}$. variasi lamina atau lapisan yang disusun sebanyak 5 lapisan dengan susunan 4 variasi yaitu: 5An (5 lapis serat gelas anyam), 5Ac (5 lapis serat gelas acak), 2C-3An (1 lapis serat karbon-3 lapis serat gelas anyam-1 lapis serat karbon), dan 2C-3Ac (1 lapis serat karbon-3 lapis serat gelas acak-1 lapis serat karbon). Ketiga jenis serat yang digunakan ditunjukkan pada Gambar 1 . Resin yang digunakan adalah polyester BQTN 157-Ex yang diperoleh dari PT. Justus Kimia Raya, Semarang. (a)

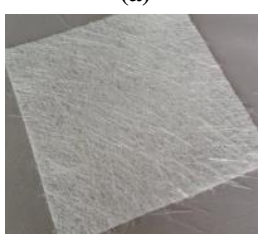

GAMBAR 1. a) Glass Fiber CSM-220, b) Glass Fiber WR-200, c) Carbon Fiber WR 200
Manufaktur Komposit Hybrid Lamina

Manufaktur pembuatan blade Turbin Savonius dimulai dari gambar disain blade dengan software Autodesk Inventor (Gambar 2). Komposit hybrid lamina diproses menggunakan metode VI (Vacuum Infusion) pada pembuatan panel dan blade turbin sovenius. Pembuatan VI menggunakan kevakuman tekanan udara pada tabung Resin Trap, untuk mengalirkan resin ke dalam cetakan (molding). Tekanan yang digunakan pada pembuatan blade adalah sebesar 0,8 Bar untuk luas maksimal $2500 \mathrm{~cm}^{2}$ pada daya pompa 3/4 Hp (Yudhanto et al., 2018). 


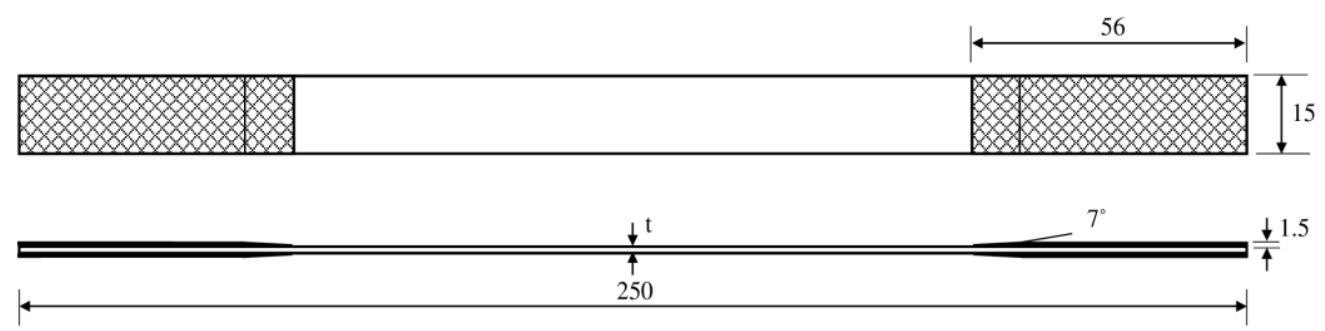

GAMBAR 4. Spesimen uji tarik komposit laminate ASTM D3039 (mm)

Gambar 3 menunjukkan bahan-bahan yang digunakan pada metode VI diantaranya adalah peel-ply, flow-media, bagging film, sealent tape, spiral tube, flow tube in and out dan $T$ connector.

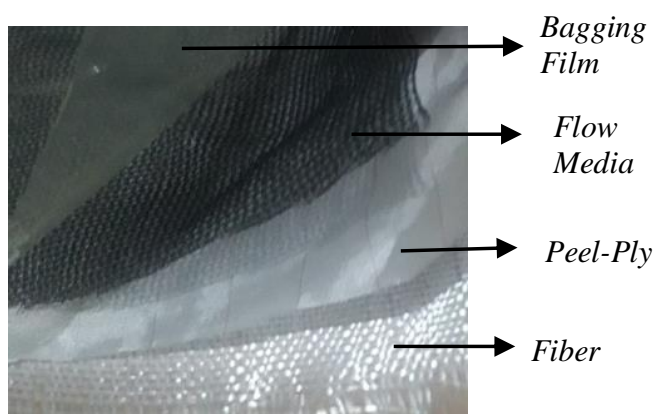

GAMBAR 3. Susunan bahan pada proses VI

Peel-ply berfungsi memudahkan lapisan serat untuk diambil ketika sudah menjadi produk komposit. Flow media berfungsi mengalirkan resin ke dalam cetakan. Bagging film membuat kevakuman udara dalam cetakan/molding. Flow tube mengalirkan resin masuk ke dalam cetakan dan mengeluarkan udara dalam cetakan. Spiral Tube dihubungkan dengan flow tube dengan T-connector, berfungsi mendistribusikan resin secara merata.

\section{Proses Manufaktur dengan VI}

Gambar 5 menunjukkan proses manufaktur blade savonius menggunakan metode VI. Alat utama pada proses ini adalah adanya Resin Trap dengan dilengkapi gauge meter dengan data 0-1 bar. Pompa Vacuum 3/4 hp untuk menghisap udara dalam tabung Resin Trap sehingga membuat kevakuman pada molding. Instalasi saluran dibuat dengan 1 saluran masuk (in) dan 2 keluar (out) melalui flow tube dengan pola aliran samping dibantu spiral tube. Proses curing resin berlangsung 20 menit sehingga cairan resin harus dapat memenuhi cetakan kurang dari waktu curing.

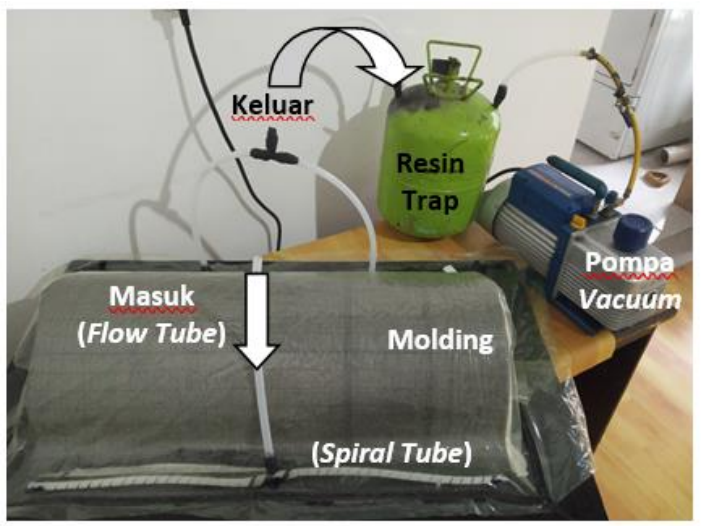

GAMBAR 5. Proses pemvakuman blade mengguanakan metode VI

Pembuatan specimen uji tarik diawali dengan pembuatan panel komposit hybrid sebelum produk blade dibuat. Panel komposit hybrid, dipotong sesuai dengan standar uji Tarik untuk komposit laminate yaitu standar uji ASTM D3039 yang dapat dilihat pada Gambar 4. Pengujian tarik menggunakan mesin uji Tarik UTM (Universal Machine Testing).

\section{Pengujian Tarik}

Pengujian tarik bahan menggunakan UTM untuk mengetahui nilai tegangan patah maksimum dan data regangan. Persamaan yang digunakan;

$\sigma=\frac{F}{A}$,
$\varepsilon=\frac{\Delta L}{L_{n}}$, 
$E=\frac{\sigma}{\varepsilon}$

Dengan catatan, $\sigma$ adalah tegangan $\left(\mathrm{N} / \mathrm{mm}^{2}\right), F$ adalah gaya $(\mathrm{N})$ dan $\mathrm{A}$ adalah luas penampang $\left(\mathrm{mm}^{2}\right)$. Regangan $(\varepsilon)$ adalah selisih hasil perpanjangan dibagi dengan Panjang mula $\left(\mathrm{L}_{\mathrm{o}}\right)$ dengan satuan \%. Modulus elastisitas (E) adalah tegangan dibagi dengan regangan material.

\section{HASIL DAN PEMBAHASAN}

Hasil uji kekuatan tarik (tensile strength) dan modulus elastisitas paling tinggi didapat pada variasi dua serat karbon dan tiga gelas anyam 2C-3An sebesar $219 \mathrm{MPa}$ dan modulus elastisitas 6,8 GPa (Gambar 6). Kekuatan paling rendah didapat pada variasi lima lapis serat gelas acak dan anyam. Untuk variasi $5 \mathrm{Ac}$ sebesar $129 \mathrm{MPa}$ dan modulus elastisitas sebesar 3,4 GPa dan variasi 5 An sebesar 150 $\mathrm{MPa}$ dan modulus elastisitas sebesar $3 \mathrm{GPa}$.

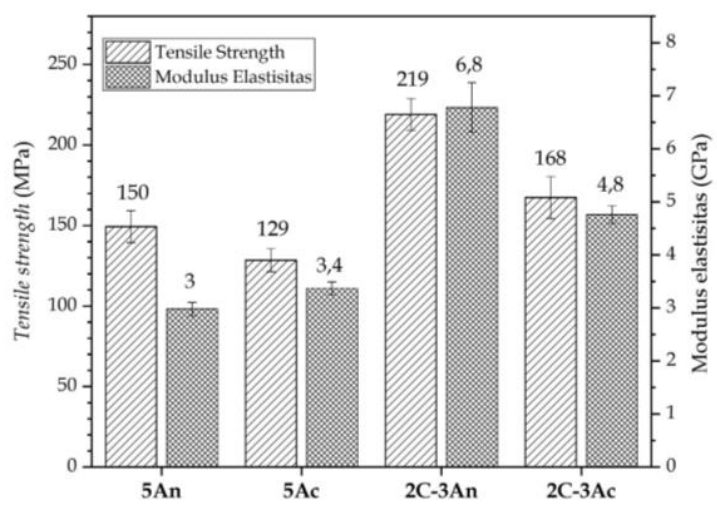

GAMBAR 6. Kekuatan tarik dan modulus elastisitas komposit hybrid laminate (a)

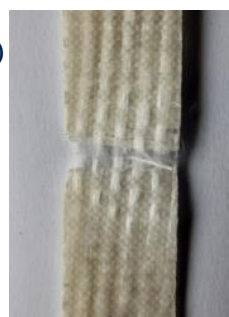

(b)

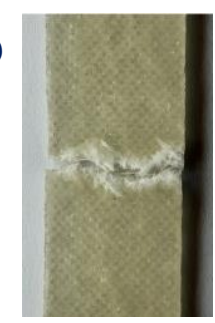

(c)

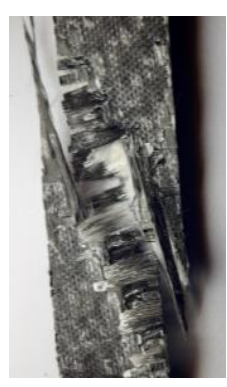

(d)

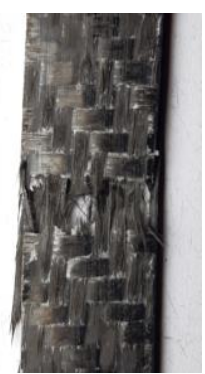

GAMBAR 7. Foto makro patahan uji tarik

(a) Fiber pull out, (b) Brittle fracture, (c) Splitting fracture with fiber pull out, (d) Fiber pull out

Hasil patahan setelah uji tarik dapat dilihat pada Gambar 7. Gambar 7 (a) menunjukkan jenis patahan fiber pull out pada variasi gelas 5An. Gambar 7 (b) menunjukkan jenis patahan getas pada variasi gelas acak 5Ac. Gambar 7 (c) tersebut terlihat patahan yang ulet terlihat dari jenis patahan splitting fracture diikuti fiber pull out untuk variasi hybrid 2C-3An. Gambar 7 (d) menunjukkan jenis patahan fiber pull out pada bagian serat karbon untuk variasi hybrid 2C-3Ac.

Densitas komposit hybrid yaitu perbandingan massa komposit dibagi dengan volume komposit untuk masing-masing variasi dapat dilihat pada Gambar 8.

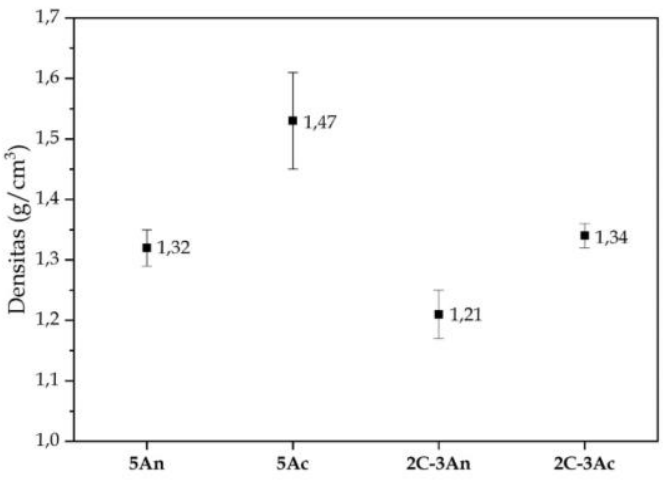

GAMBAR 8. Densitas komposit hybrid laminate

Hasil yang diperoleh dari masing-masing vasriasi didapat densitas terendah diperoleh pada variasi 2C-3An (komposit hybrid) dengan nilai $1,21 \mathrm{~g} / \mathrm{cm}^{3}$ sedangkan paling berat di dapat pada glass fiber 5Ac (komposit gelas acak) dengan nilai $1,47 \mathrm{~g} / \mathrm{cm}^{3}$.

Hasil pembuatan komposit hybrid lamina yang ditunjukkan pada Gambar 9 dipilih berdasarkan nilai kekuatan tarik dan modulus elastisitas yang terbaik dari ke empat variasi 
susunan lamina. Variasi tersebut juga harus memiliki densitas yang rendah dibandingkan variasi lain karena kecepatan putaran blade semakin cepat apabila massa blade semakin ringan. Pemilihan susunan hybrid untuk pembuatan blade turbin Savonius tersebut dipilih variasi komposit hybrid lamina 2C-3An untuk dapat diaplikasikan pada pembuatan blade turbin Savonius. Pembuatan produk blade dengan menggunakan komposit mengurangi penggunaan material plat baja ringan yang sering digunakan pada pembuatan blade turbin. Material komposit hybrid Carbon/Glass memiliki banyak keuntungan yaitu sangat ringan, ketahanan terhadap suhu lingkungan dan tingkat keasaman daerah pantai.

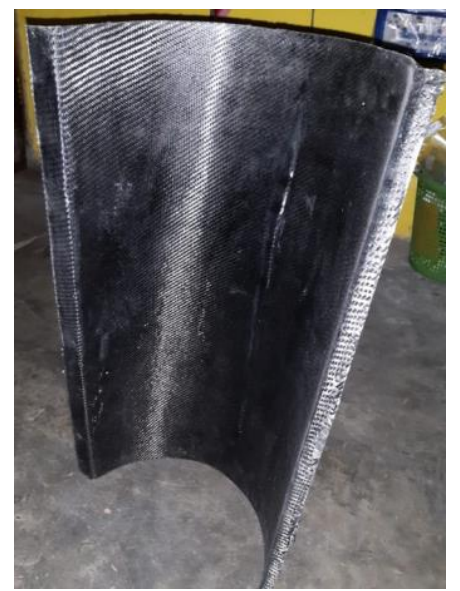

GAMBAR 9. Hasil produk blade komposit hybrid laminate 2C-3An

\section{KESIMPULAN}

Pemilihan material komposit untuk pembuatan blade Turbin Savonius dipilih dengan mempertimbangkan kekuatan mekanis paling baik dan densitas yang rendah dipilih pada variasi 2 lapisan karbon dan 3 lapisan gelas anyam (2C-3An) dengan nilai kekuatan tarik $219 \mathrm{MPa}$, modulus elastisitas 6,8 $\mathrm{GPa}$, dan densitas komposit $1,21 \mathrm{~g} / \mathrm{cm}^{3}$.

\section{UCAPAN TERIMA KASIH}

Penelitian ini dilaksanakan dengan dana hibah penelitian LP3M Universitas Muhammadiyah Yogyakarta (UMY), kontrak No. 034/PENLP3M/I/2020. Penulis juga mengucapkan terima kasih kepada Putra Dharma Haryanto selaku mahasiswa yang membantu manufaktur komposit di Lab. Komposit, Teknologi Mesin, Program Vokasi UMY.

\section{DAFTAR PUSTAKA}

Jesthi, D.K., Nayak, A., Mohanty, S.S., Rout, A.K. and Nayak, R.K. 2018, June. Evaluation of mechanical properties of hybrid composite laminates reinforced with glass/carbon woven fabrics. In IOP Conf. Ser. Mater. Sci. Eng. (Vol. 377, p. 012157).

Joseph, K., Tolêdo Filho, R.D., James, B., Thomas, S. and De Carvalho, L.H., 1999. A review on sisal fiber reinforced polymer composites. Revista Brasileira de Engenharia Agrícola e Ambiental, 3(3), pp.367-379.

Mawardi, I. and Hanif, H. 2018. Sifat Mekanis Komposit Polimer Hibrid Diperkuat Serat Sabut Kelapa-E-Glass. ETHOS: Jurnal Penelitian dan Pengabdian kepada Masyarakat, 6(2), pp.297-304.

Pradana, A.J., Nugroho, G. and Musyafa, A., 2013. Rancang Bangun Turbin Angin Vertikal Jenis Savonius dengan Variasi Profil Kurva Blade untuk Memperoleh Daya Maksimum. Jurnal Teknik POMITS, 7(7), pp.1-6.

Standard ASTM D3039. 2008. Standard Test Method for Tensile Properties of Polymer Matrix Composite Materials. ASTM International, West Conshohocken, PA.

Wisnujati, A. and Yudhanto, F. 2018. Analisis kekuatan mekanik exhaust cover komposit hybrid untuk sepeda motor dengan metode vacuum infusion. Turbo: Jurnal Program Studi Teknik Mesin, $7(1)$.

Yudhanto, F., Sudarisman, S. and Ridlwan, M., 2016. Karakterisasi Kekuatan Tarik Komposit Hybrid Lamina Serat Anyam Sisal dan Gelas Diperkuat Polyester. Semesta Teknika, 19(1), pp.48-54.

Yudhanto, F. and Rochardjo, H.S., 2018, May. Application of taguchi method for selection parameter bleaching treatments against mechanical and physical properties of agave cantala fiber In. In IOP Conference Series: Materials Science and Engineering (Vol. 352, No. 1, p. 012002). 